\title{
KNOWLEDGE ON CHILDREN'S ATTENTION DEFICIT HYPERACTIVITY DISORDER AMONG SCHOOL TEACHERS IN CHITWAN
}

\author{
Lamichhane $\mathrm{S}^{1}$, Sharma $\mathrm{P}^{2 \dagger}$ \\ ${ }^{1}$ Manmohan Memorial Institute of health Sciences, Soalteemode, Kathmandu. \\ ${ }^{2}$ Lecturer of Nursing, Manmohan Memorial Institute of Health Sciences, Soalteemode, \\ Kathmandu \\ ${ }^{\dagger}$ Corresponding author: Poojan Sharma Departmetn of Nursing, Manmohan Memorial \\ Institute of Health Sciences, Soalteemode, Kathmandu. Email: poojan42@gmail.com
}

\section{ABSTRACT}

Background: attention deficit hyperactivity disorder (ADHD) is one of the most common psychiatric disorders in children and adolescents. Children with ADHD are at risk for psychological, social and academic problems so that teacher's knowledge on ADHD affects the child's academic and psychological difficulties. Objective of this study was to identify the knowledge about ADHD in children among school teachers and identify association between knowledge and selected variables.

Methods: We used descriptive and cross sectional research design. Structured self administered questionnaire was used to collect data. Total 9 public and private schools were randomly selected for study. Calculated sample size was 380. However, 328 teachers returned the questionnaire (response rate was 86\%). Collected data were entered in SPSS for analysis. Descriptive and inferential statistics were used for analysis of data.

Results: among 328 teachers, 68.3\% had inadequate knowledge while $31.7 \%$ had adequate knowledge on ADHD. Age and years of teaching were significantly associated with knowledge of ADHD, however, sex of the teachers and type of school were not associated with knowledge of ADHD.

Conclusion: knowledge of ADHD among school teachers is still inadequate which suggests the need for effective health education programme on ADHD for understanding and managing the behavioural and psychological problems caused by ADHD among school children.

Keywords: ADHD, Knowledge, School teachers, Chitwan 


\section{INTRODUCTION}

Attention deficit hyperactivity disorder is a developmentally inappropriate degree of inattention, impulsiveness, and hyperactivity. Behavior of children with ADHD stirs up negative responses from others and repeated exposure to negative feedback adversely affects child's self-concept. This disorder affects the child's written and adaptive skills, social status, and self esteem. ${ }^{1}$

ADHD is the most common psychiatric disorders in child and adolescent and children with this disorder are at risk for academic and psychological difficulties. ${ }^{2}$ A meta-analysis of 175 research studies worldwide showed that the prevalence of ADHD in children aged 18 and below is estimated 7.2\%. ${ }^{3}$ A study from United States showed ADHD is reportedly the most pervasive disorder of childhood affecting approximately $3 \%$ to $5 \%$ of school-aged children with prevalence rates increasing significantly over the past two decades. ${ }^{4}$ A study from Mumbai India in 40 Kindergarten showed that, the prevalence of ADHD among children aged 4-6 was $12.2 \% .^{5}$ A hospital based study in Nepal showed 41\% prevalence of ADHD among school children. ${ }^{6}$

A total knowledge score on ADHD was lower than mean score among school teacher in Trinidad \& Tobago. $^{7}$ A study from South Arica in 2015 found that 45\% primary school teachers had knowledge on ADHD while 31\% did not know the answer and 22\% provided incorrect response. ${ }^{8}$ A study in Sri Lanka found that more than $80 \%$ of primary teachers believed parents to be blamed for child's ADHD. The majority of participating teachers believed that behavioural disturbances caused by ADHD children were deliberate and hateful. However, teachers who had training in child psychology recorded a significantly higher knowledge and had a more favourable attitude. ${ }^{9}$

\section{Materials and Methods}

The descriptive cross-sectional study was used to find out the knowledge of school teachers on ADHD in 9 schools of Chitwan district. The study population were primary and secondary school teachers of public and private schools of Chitwan district. We selected 9 schools randomly from school list provided by district education office of Chitwan. Sample size was calculated by taking P- 45\%. [8] and 5\% absolute precision. Calculated sample size was 380. Only 328 teachers returned the filled questionnaire (86\% response rate). 


\section{Original Article}

Structured self-administered questionnaire was used to collect data. Some modification was done to KADDS tool. ${ }^{10}$ Total 23 questions scale was used to identify knowledge. Each question was marked one. Mean score was calculated. Below mean was considered inadequate score and above mean score was considered as an adequate knowledge score. Before collection of data, pre-test of tool was done with 33 school teachers of Chitwan district. Internal consistency of modified KADDS tool was checked pre-test data by cronbach's alpha (0.77) which was sufficient. ${ }^{11}$ Certain questions related to diagnosis and treatment of ADHD on KADDS tool were removed as all teachers did not provide response on that because those questions were not necessary to know by the school teachers in our context. The data were analysed using Statistical Package for Social Sciences (SPSS).

We took ethical approval from Institutional Review Committee (IRC), of Manmohan Memorial Institute of Health Sciences (Ref. 108/73). Written informed consent was taken from school teachers. The research was not harmful to school teachers, the collected information and the findings were used only for the purpose of the study

\section{RESULTS}

Among 328 teachers, majority 114 (35\%) were age group between 30-40 years. Above 40 years and aged 20-30 were in same numbers 107(33\%). Male and female teachers were 166(51\%) and 162(49\%) respectively. Majority 147(45\%) of the teachers had completed bachelor degree 147(45\%) and 3(1\%) teachers had completed SLC.

Table 1: Work related Characteristics of Teachers

$$
\mathbf{n}=328
$$

\begin{tabular}{lll}
\hline Characteristics & Frequency & Percentage \\
\hline Years of teaching & & \\
Less than 5 years & 69 & $21 \%$ \\
$5-10$ years & 84 & $26 \%$ \\
$11-15$ years & 83 & $25 \%$ \\
$16-20$ years & 92 & $28 \%$ \\
Teaching level & & \\
Primary level & 132 & $40 \%$ \\
Lower secondary & 87 & $27 \%$ \\
\hline
\end{tabular}


Original Article

\begin{tabular}{lll}
\hline Higher secondary & 109 & $33 \%$
\end{tabular}

\section{Types of school}

Private school

159

$48 \%$

Government school

169

$52 \%$

Table 2 most of the teachers 92(28\%) had teaching experience between 16-20 years and 69(21\%) teachers had less than 5years teaching experience. Two fifth teachers 132(40\%) were teaching in primary and 87(27\%) teachers were teaching in lower secondary students. More than half 169(52\%) of teachers were from government school and 159(48\%) were from private school.

Table 2: Knowledge on Attention Deficit Hyperactivity Disorder (ADHD) among Teachers

Knowledge related statements
Frequency/percentage

Yes No

\section{General Information}

Have you ever heard about Attention Deficit Hyperactivity 104(32\%) 224(68\%)

Disorder?

ADHD is neuro-developmental psychiatric disorder in child 148 (45\%) 180(55\%) and adolescent.

ADHD children often have difficulties organizing task and 222 (68\%) 106 (32\%) activities.

Knowledge on signs and symptoms and Diagnosis

ADHD suggest 3 symptoms: inattention, hyperactivity and $273(83 \%) 55$ (17\%) impulsivity.

Symptoms of poor attention in children are found difficulty in $268(82 \%) 60$ (18\%) listening to others and losing interest and forgetfulness. 
One symptom of ADHD children is that they have been 152 (46\%) 176 (54\%) physically cruel to other people.

Overacting and done every activity without thinking is the 137(42\%) 191(58\%) symptom of impulsivity.

Symptoms of depression are found more frequently in ADHD 183(56\%) $\quad$ 145(44\%) children than in non -ADHD children.

ADHD children are frequently distracted by extraneous 168(51\%) 160 (49\%) stimuli

It is common for ADHD children to have an inflated sense of $\quad 125(38 \%) \quad$ 203(62\%) self esteem or grandiosity.

In order to be diagnosed with ADHD, the child symptoms 120(37\%) 208(63\%) must have been present before age 7 .

Reducing dietary intake of sugar or food addictives is 62(19\%) 266(81\%) generally effective in reducing the symptoms of ADHD.

It is possible for an adult to be diagnosed with ADHD. $\quad 211(64 \%) \quad 117(36 \%)$ ADHD children generally experience more problems in 210(64\%) 118(36\%) unfamiliar situations than in familiar situations.

\section{Treatment}

Treatments for ADHD which focus primarily on punishment 164(50\%) 164(50\%) have been found to be the most effective in reducing the symptoms of ADHD.

When treatment of an ADHD child is terminated, it is rare for $144(44 \%) \quad 184(56 \%)$ the child's symptom to return. 
Original Article

Parent and teacher training in managing an ADHD child are 266(81\%) $\quad$ 62(19\%) generally effective when combined with medication treatment.

Antidepressant drug have been effective in reducing symptom $\quad 140(43 \%) \quad$ 188(57\%) for many ADHD children.

Individual psychotherapy is usually sufficient for the 234(71\%) 94(29\%) treatment of most ADHD children.

Behavioral and psychological interventions for children with 235(72\%) 93(28\%) ADHD focus primarily on the child's problem in attention.

In school age children, the prevalence of ADHD in males and $183(56 \%) \quad 145(44 \%)$ females is equivalent.

If severe cases of ADHD, medication is often used before 182(55\%) 146(45\%) other behavior modification techniques are attempted.

The complication of ADHD can occur in later adolescent such ２86(87\%) 42(12\%) as accident, injuries, disposition to alcohol or drug, depression and anxiety disorder

Table 2 depicts that majority of the teachers (68\%) had not heard about ADHD. More than half (55\%) of the teachers said ADHD is not a neuro-developmental disorder. More than four fifth (83\%) teachers were aware about the three major symptoms of ADHD. More than three fourth (87\%) had knowledge about the complications of ADHD.

Table 3: Knowledge on ADHD of Children

\begin{tabular}{lll}
\hline Knowledge & Frequency & Percentage \\
\hline Adequate knowledge & 104 & $32 \%$ \\
Inadequate knowledge & 224 & $68 \%$ \\
& & \\
\hline
\end{tabular}




\section{Original Article}

Table 3 shows that more than two third 224(68\%) had inadequate knowledge and less than one third 104(32\%) had adequate knowledge on attention deficit hyperactivity disorder.

Table 4: Association between Socio-demographic Variables and Knowledge of ADHD

\begin{tabular}{llll}
\hline Characteristics & $\begin{array}{l}\text { Adequate knowledge } \\
\text { Frequency (\%) }\end{array}$ & $\begin{array}{l}\text { Inadequate knowledge } \\
\text { Frequency (\%) }\end{array}$ & P-value \\
\hline Age & & $62(57.94)$ & $0.02 *$ \\
More than 40 years & $45(42.06)$ & $84(73.68)$ & \\
$30-40$ years & $30(26.32)$ & $78(72.89)$ & 0.69 \\
$20-30$ years & $29(27.11)$ & $115(69.27)$ & \\
Sex & $51(30.73)$ & $109(67.28)$ & \\
Male & $53(32.72)$ & & \\
Female & & & \\
\hline P-value obtained from & Pearson chi-square. * Significant association at $95 \%$ confidence \\
interval &
\end{tabular}

Table 4 depicts that the age of teachers was significantly associated with knowledge of ADHD (P-0.02) whereas teacher's sex was not associated with the knowledge of ADHD (P-0.69).

Table 5: Association between works related characteristics and knowledge of ADHD

\begin{tabular}{|c|c|c|c|}
\hline Characteristics & $\begin{array}{l}\text { Adequate knowledge } \\
\text { No. (\%) }\end{array}$ & $\begin{array}{c}\text { Inadequate knowledge } \\
\text { No. (\%) }\end{array}$ & P-value \\
\hline \multicolumn{4}{|l|}{ Years of teaching } \\
\hline Less than 5 years & 17(20.73) & $65(79.27)$ & $0.00 *$ \\
\hline 5-10 years & $21(25)$ & $63(75)$ & \\
\hline 11-15 years & $22(31.43)$ & $48(68.57)$ & \\
\hline 16-20 years & $44(47.83)$ & $48(52.17)$ & \\
\hline \multicolumn{4}{|l|}{ Teaching level } \\
\hline Primary level & $44(33.34)$ & 88(66.66) & 0.19 \\
\hline Lower secondary & $21(24.14)$ & $66(75.86)$ & \\
\hline
\end{tabular}




\begin{tabular}{lll}
\hline Higher secondary & 39(35.77) & 70(64.23)
\end{tabular}

\section{Types of school}

$\begin{array}{llll}\text { Private school } & \text { 48(30.18) } & 111(69.82) & 0.56 \\ \text { Government school } & 56(33.14) & 113(66.86) & \end{array}$

P-value obtained from Pearson chi-square. * Significant association at 95\% confidence interval

Table 5 illustrates that there is significant association between years of teaching and knowledge of ADHD (p-0.00). However, teaching level (p-0.19) and types of school (p-0.56) were not associated with knowledge of ADHD.

\section{DISCUSSION}

Majority of the teachers 114 (35\%) were aged 30-40 and age above 40 years and aged 20-30 were in equal number 107 (33\%). Majority of teachers 166(51\%) were male and 162(49\%) teachers were female. In our study, 147 (45\%) had completed bachelors degree, 144(44\%) had completed master degree, 34(10\%) had completed 10+2 and 3(1\%), had completed SLC. The most of the teachers 92(28\%) had teaching experience between 16-20 years and minority of teachers 69(21\%) had less than 5year teaching experience. Two fifth teachers 132(40\%) were teaching in primary level, 87(27\%), were teaching lower secondary level and 109(33\%) were teaching in higher secondary level. More than half teachers 169(52\%) were from government school and 159(48\%) were from private school.

In our study, more than two third of teachers (68\%) had inadequate knowledge on ADHD whereas 104 (32\%) had adequate knowledge. The study from South Texas showed that, 59\% of teachers had poor knowledge and only $10.2 \%$ had good knowledge about attention deficit hyperactivity disorder. ${ }^{12}$

\section{Association between Socio-demographic Variables and Knowledge of ADHD}

Our study revealed that teacher's knowledge on ADHD is significantly associated with the age of teachers. This finding is consistent with the result of a study conducted in 2017 which showed significant relation between mean knowledge score of ADHD and age of primary school teachers (P-0.0001). ${ }^{12}$ 
Our study revealed that year of teaching (P-0.00) was significantly associated with the knowledge of ADHD. This is in line (P-0.0001) with the finding of a study conducted in Ezypt. $^{12}$

Our study showed no any significant association of sex of teachers (p-0.69) with knowledge on ADHD. Similar finding was on a study conducted in Ezypt that there was no any association (p-0.058) between sex of the teachers and knowledge of ADHD. ${ }^{12}$

In this study there is no any significant association of types of school \{public and private (p0.56) with knowledge of ADHD. Contrary to the finding, knowledge score of ADHD among state school teacher (private school) had higher in comparison with state religious school (state funded faith school). ${ }^{13}$

\section{CONCLUSION}

Findings of study revealed that knowledge towards attention deficit hyperactivity disorder (ADHD) is still inadequate which suggests there is need for effective health education programme on ADHD for school teachers. Teachers training and mental health promotion programme should be conducted in school; it helps to enhance teacher's understandings of children’s behavioural and psychological problems associated with ADHD.

\section{ACKNOWLEDGEMENT}

We would like to provide our gratitude to Manmohan Memorial Institute of Health Sciences for providing platform to conduct the study. We would like to provide thanks to the school teachers of selected schools at Chitwan for providing their valuable time and information for the study.

\section{REFERENCES}

1. Hockenberry MJ, Wilson D. Wong's Essentials of Pediatric Nursing, $8^{\text {th }}$ ed. India, 2012. Elsevier India Private Limited; PP. 559.

2. Ghanizadeh A, Bahredar MJ, Moeini SR. Knowledge and attitudes towards attention deficit hyperactivity disorder among elementary school teachers, Patient Education and Counseling, 2006; Retrived from 
Original Article

https://www.semanticscholar.org/paper/Knowledge-and-attitudes-towards-attention deficit-Ghanizadeh-Bahredar/383607fd0b58a839d88f9ffdeef0ecf3de57bcd8

3 Rae T, Sanders S, Doust J, Beller, E, Glasziou P. Prevalence of Attention Deficit/Hyperactivity Disorder: A Systematic Review and Meta-analysis. Pediatrics, 2015; 135(4), 994-1001. DOI: 10.1542/peds.2014-3482

4. Akinbami LJ, Liu X, Pastor PN, Reuben C. Attention deficit hyperactivity disorder among children aged 5-17 years in the United States. Data Brief NCHS, 2011; 70:1998-2009. Retrieved from https://www.cdc.gov/nchs/products/databriefs/db70.htm

5. Suvarna BS, Kamath A. Prevalence of attention deficit disorder among preschool age children. Nepal Med Coll J, 2009; 11(1):1-4. Retrieved from https://www.ncbi.nlm.nih.gov/pubmed/19769227

6. Rimal HS, Pokharel A. Prevalence of Attention Deficit Hyperactivity Disorder among School Children and Associated Co-morbidities - A Hospital Based Descriptive Study. Kathmandu University Medical Journal, 2016; 14(55). Retrieved from www.kumj.com.np/issue/55/226-230.pdf

7. Youssef MK, Hutchinson G, Youssef FF. Knowledge of and attitudes toward ADHD among teachers, Sage Journal 2015; 5(1). DOI: https://doi.org/10.1177/2158244014566761

8. Topkin B, Roman NV, Mwaba K. Attention deficit disorder (ADHD): primary school teachers' knowledge of symptoms, treatment and managing classroom behaviour. SA Journal of Education, 2015; 35(2). DOI: 10.15700/saje.v35n2a988

9 Rodrigo MD, Perera D, Eranga VP, Williams SS, Kuruppuarachchi KA. The knowledge and attitude of primary school teachers in Sri Lanka towards childhood attention deficit hyperactivity disorder. Ceylon Med J, 2011; 56(2): 51-4. Retrieved from https://www.ncbi.nlm.nih.gov/pubmed/21789864

10. Sciutto MJ, Terjesen MD, Bender Frank AS. Teachers' knowledge and misperceptions of Attention-Deficit/Hyperactivity Disorder. Psychology in the 
Original Article

Schools, 2000; 37(2): 115-122. DOI: http://dx.doi.org/10.1002/(SICI)15206807(200003)37:2<115::AID-PITS3>3.0.CO;2-5

11. Tavakol M, Dennick R. Making sense of Cronbach’s alpha. International Journal of Medical Education. 2011; 2:53-55. DOI: 10.5116/ijme.4dfb.8dfd

12. Safaan NA, Nagar SAE, \& Saleh AG. Teachers' knowledge about attention deficit hyperactivity disorder among primary school children, American Journal of Nursing Research, 2017; 5(2): 42-52.

13. Albaldes LS. Knowledge about ADHD among teachers in the Educational System (The State and State Religious Sectors) in Israel. Studia Edukacyjne nr, 2015; 36:443-463. DOI: $\underline{10.14746 / \text { se.2015.36.25 }}$ 